\title{
Bilateral neck fracture in bimodular femoral stem after primary total hip arthroplasty: a case report
}

\author{
Samo K. Fokter ${ }^{1}$ (D), Nenad Gubeljak², Jožef Predan², Jure Sevšek ${ }^{3}$, Jan Zajc ${ }^{1 *}$ (D) and Zmago Krajnc ${ }^{1}$
}

\begin{abstract}
Background: Bi-modular stems were introduced in primary total hip arthroplasty (THA) to enable better control of the femoral offset, leg length, and hip stability. Despite numerous reports on modular femoral neck fractures, some designs are still marketed worldwide. While the risk factors for the sudden failure are multifactorial and mostly known, the timing of this new THA complication is not predictable by any means.

Case presentation: In this report, the literature regarding one of the most popular bi-modular stems with specific neck-stem coupling (oval Morse taper) is reviewed and illustrated with a case of bilateral modular neck fracture in a patient with idiopathic aseptic necrosis of femoral heads treated with primary bi-modular THA. Because of bilateral modular femoral neck fracture, which occurred 3 years on the left side and 20 years after implantation on the right side, the patient required a total of 6 revisions and 208 days of hospitalized care.

Conclusion: To our knowledge, this is the first report of bilateral modular neck fracture in a single patient. Even though the same surgeon performed both operations and used the same neck length and orientation, fractures occurred with a 17-year time difference after implantation. This shows that we cannot predict with certainty when a fracture might occur. Orthopaedic surgeons should use bi-modular stem designs for primary THA very cautiously.
\end{abstract}

Keywords: Bi-modular femoral stem, Case report, Modular femoral neck, Neck fracture, Taper corrosion, Titanium alloy, Total hip arthroplasty complication

\section{Background}

The bi-modular femoral stem is a recent innovation in primary total hip arthroplasty (THA) that enables the orthopaedic surgeon a more anatomically correct restoration. Single-centre studies reported excellent results with titanium alloy made stems and modular necks even in the long term [1]. However, some producers were forced to remove their implant from the market or change the neck material to cobalt-based alloys due to

\footnotetext{
* Correspondence: jzajc11@gmail.com

'Department of Orthopaedic Surgery, University Medical Centre, 5 Ljubljanska street, SLO-2000 Maribor, Slovenia

Full list of author information is available at the end of the article
}

an increase of titanium alloy modular femoral neck failures [2].

Different types of corrosion can develop on the stemneck junction. Studies have linked implant failures to mechanically assisted crevice corrosion (MACC), which also includes the most common damage process fretting corrosion [3]. Corrosion products can cause adverse local tissue reactions that lead to THA failure [4].

Several orthopaedic studies on bi-modular THA's have identified risk factors that can lead to modular neck fracture. These include time since implantation, a long neck, a cobalt-chromium alloy neck, younger age, male sex, and higher BMI [4].

This is the first report of a case with bilateral titanium-titanium alloy modular neck fracture in a

(c) The Author(s). 2021 Open Access This article is licensed under a Creative Commons Attribution 4.0 International License, which permits use, sharing, adaptation, distribution and reproduction in any medium or format, as long as you give appropriate credit to the original author(s) and the source, provide a link to the Creative Commons licence, and indicate if changes were made. The images or other third party material in this article are included in the article's Creative Commons licence, unless indicated otherwise in a credit line to the material. If material is not included in the article's Creative Commons licence and your intended use is not permitted by statutory regulation or exceeds the permitted use, you will need to obtain permission directly from the copyright holder. To view a copy of this licence, visit http://creativecommons.org/licenses/by/4.0/ The Creative Commons Public Domain Dedication waiver (http://creativecommons.org/publicdomain/zero/1.0/) applies to the data made available in this article, unless otherwise stated in a credit line to the data. 
patient treated with primary THA using current-generation stem designs with $9 \times 18 \mathrm{~mm}$ rectangular cross-section Morse taper as a method of intraoperative stem-neck fixation (Microport Orthopedics Inc., Arlington, TN, USA, formerly Cremascoli Ortho, Milan, Italy). Proximally, the Ti6Al4V modular neck was equipped with standard 12/14 $\mathrm{mm}$ cylindrical taper for head-neck coupling. Distally, the rectangular vertices were rounded by fillets; taper angles in the flat and curved sections were machined to $4^{\circ}$. This type of distal taper geometry was not changed even though femoral stem's design changed with different manufacturers. With its three different neck versions (straight, valgus/varus and ante/retro; both deviations for $8^{\circ}$ or $15^{\circ}$ ) and two different neck lengths (short and long), it enables the surgeon to properly restore anatomical conditions in most patients [5].

\section{Case presentation}

A 38-year-old male with body mass index (BMI) $31.5 \mathrm{~kg} /$ m2 was presented in 1998 with more than 12 months of progressive pain in both hips. Radiographs and computer tomography scanning revealed avascular necrosis of the femoral heads (Ficat stage IV on the right and Ficat stage III on the left side). The right hip was treated with an uncemented THA through a standard posterior approach. A screw-in titanium-alloy (TiAl6V4) acetabular cup size 56 $\mathrm{mm}$ with polyethylene insert (RCM, Cremascoli Ortho) was inserted and the used femoral component was a size 6 proximally plasma-spray hydroxyapatite-coated, and anatomically shaped titanium-alloy modular stem (An.C.A. Fit, Cremascoli Ortho) with long straight titanium modular neck of the same material and $28-\mathrm{mm},+3.5 \mathrm{~mm}(\mathrm{~L})$ length cobalt-chromium (Co-Cr) femoral head. Next year, the patient's left hip was treated through a standard posterior approach by the same orthopaedic surgeon with a $60 \mathrm{~mm}$ screw-in titanium-alloy acetabular cup with polyethylene insert (RCM, Cremascoli Ortho) and the size 7 femoral component (An.C.A. Fit, Cremascoli Ortho) with long straight titanium modular neck and $28-\mathrm{mm}$ alumina ceramic (Biolox Forte, CeramTec, Plochingen, Germany) femoral head with $+3.5 \mathrm{~mm}$ (L) length. The same surgeon performed both surgeries and the patient recovered from both with no postoperative complications.

Three years after primary left THA, the patient presented with sudden left groin pain and inability to bear weight on the affected leg. Radiographs revealed a fracture of the left modular femoral neck (Fig. 1). At revision, no signs of polyethylene wear, local tissue adverse reaction or pseudotumor formation were present. However, it was impossible to disengage the modular neck from the femoral taper. An extended trochanteric osteotomy was performed to remove the original implant and a Wagner-type revision modular stem (Limacorporate S.p.A., Udine, Italy) was inserted. Tissue samples were sent for bacteriology and have remained sterile. However, the patient underwent subsequent revision surgeries for stem subsidence, instability and eventually for Staphyloccocus Epidermidis infection. The infection was eliminated through a twostaged procedure and the patient was finally successfully reconstructed in 2017 with Alloclassic Zweymüller SL stem, Continuum acetabular component and Biolox Delta

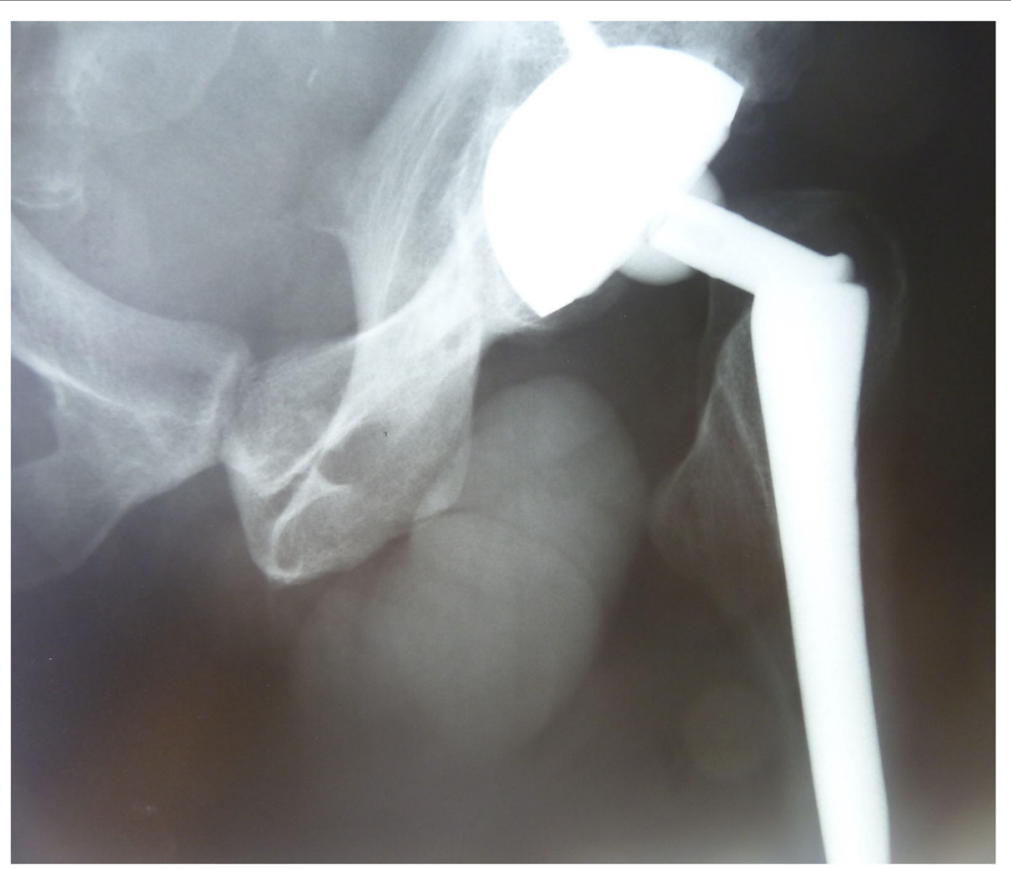

Fig. 1 Emergency room X-ray of the left hip with fractured modular femoral neck 3 years after primary THA 
ceramic femoral head (Zimmer Biomet). Radiographs taken 2 years after revision demonstrated stable fixation of all THA components of the left hip.

Unfortunately, 20 years after the right THA insertion, the patient presented again to the Emergency Clinics with a fracture of the right-side modular neck (Fig. 2). At revision, no significant local tissue adverse reaction or pseudotumor formation were present. Again, it was impossible to disengage the modular neck from the femoral taper (Fig. 3). The femoral component was extracted via a single longitudinal proximal splitting and two-chisel technique. The acetabular component was revised as well due to excessive polyethylene wear. A replacement liner was not available. The hip was reconstructed with a long Wagner-type revision stem (Limacorporate), Continuum acetabular component (Zimmer Biomet) and ceramic femoral head (Biolox Delta). Tissue samples taken during revision surgery and sent for cultures remain sterile. Immediate postoperative course was uneventful and patient was discharged as usual. However, he was readmitted 1 month after surgery with signs of deep wound infection. The revision procedure was debridement, antibiotics and implant retention (DAIR) with exchange of femoral head and liner only. Operative cultures found Cutibacterium (Propionibacterium) acnes. The patient was treated with antibiotics for 3 months.

14 months after the last revision, the patient was complaining of mild occasional pain and ambulated without walking aids or shoe lift. The patient's Harris Hip Score (HHS) was 84 for the right hip and 87 for the left hip, respectively. His University of California at Los Angeles (UCLA) activity score $(\min 0-\max 10)$ was 4 . The SF36 outcome scores for general health, health change, pain, physical functioning, and limitations due to physical health were $75,50,60,45$ and $25 \%$, respectively, $40 \%$ each for social functioning, emotional wellbeing and energy/fatigue, and $0 \%$ for role limitations due to emotional problems. The radiographs demonstrated stable fixation of all THA components of both hips (Fig. 4).

\section{Discussion}

Bi-modular stem designs offer surgeons an intraoperative choice of neck version and length independently of the stem size, which has led to their worldwide popularity. There are important differences in femoral neck length, shaft diameter, caput-column-diaphysis (CCD) angle, neck version, and neck offset, and modularity enables the orthopaedic surgeon to adapt to those differences [1]. Excellent results with titanium-titanium alloy made stems and modular necks were reported in singlecentre studies [5]. Despite these advantages, several studies reported an increase in titanium alloy modular femoral neck failures $[2,6,7]$. In a study of two groups of THA patients, Duwelius et al. looked for differences in anatomical hip restoration and revision rates between nonmodular and modular stems [8]. A total of 284 patients with nonmodular stems (Zimmer M/L Taper) and 594 patients with modular stems (Zimmer M/L Taper Kinectiv) were followed up with a mean of 2.4 years (maximum 5.9 years). Clinical and radiographic measurements of leg length and offset were done before and after surgery. Clinical evaluations included Harris Hip and SF-12 scores, respectively. With no differences in outcome scores, the authors concluded that modular stems offered no added value over standard nonmodular stems [8].

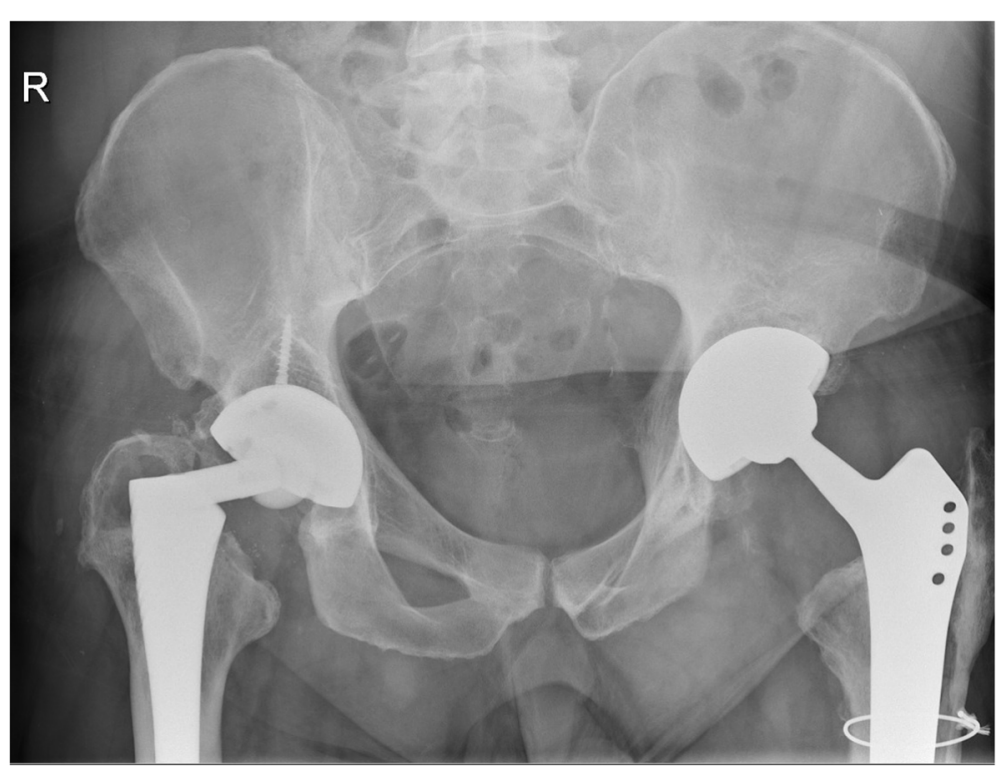

Fig. 2 Pelvic X-ray with modular neck fracture shown on the right and situation 1 year after fourth revision of the left THA, respectively 


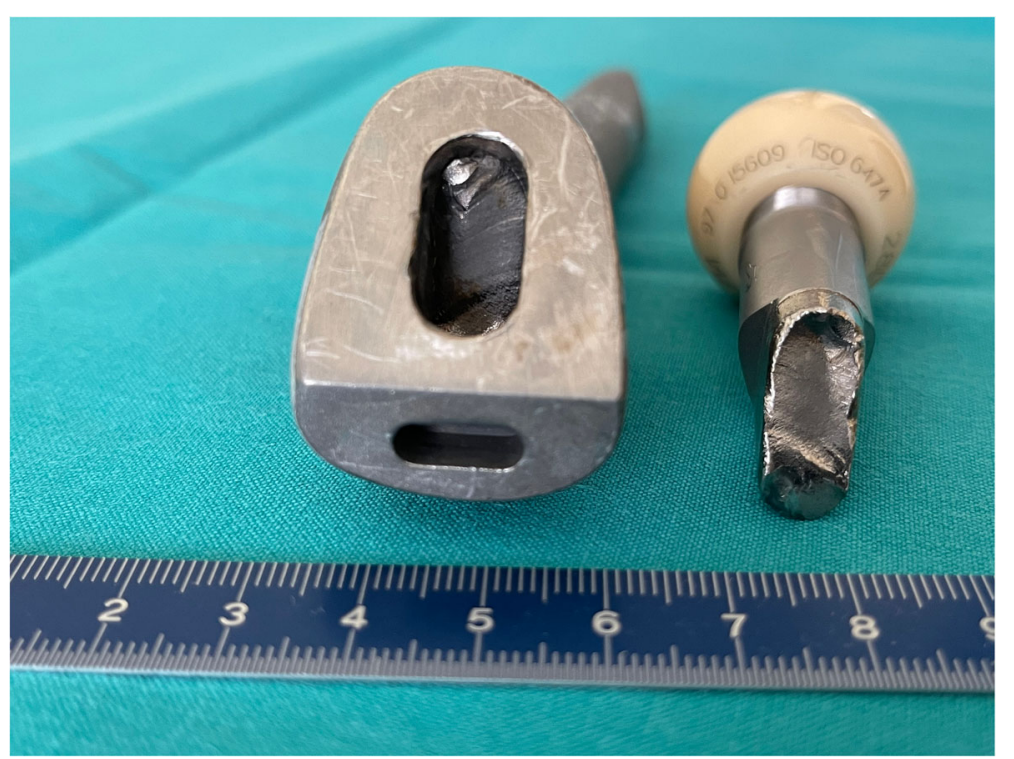

Fig. 3 Optical photograph of the fractured surface of the modular neck with the distal part still engaged in the conical cavity of the femoral stem

Different specific types of corrosion at the stem-neck junction were found responsible for exchangeable neck failures. In 2014, Mumme et al. submerged standardized alloys (TiAl6V4, CoCr29Mo, FeCrNiMoMnNbN and pure titanium) in human serum and measured in vitro serum levels of metal ions [9]. Elevation of in vitro ions concentration shows that electrochemical corrosion occurs without the need for mechanical load [9]. Types of corrosion that can develop in orthopaedic implants include uniform corrosion attack, galvanic corrosion, fretting corrosion, crevice corrosion, pitting corrosion, intergranular corrosion, leaching, and stress-corrosion cracking [10]. MACC at stem-neck junction was shown to release metal debris that caused local tissue reactions like those found in failed THA-s [11-14].

Titanium alloy is suitable for non-modular prosthesis due to its passive oxide layer that protects it from uniform corrosion. Fretting corrosion is caused by oscillating micro motion between two surfaces [15]. In modular stem prosthesis, micro movements at the stem-neck junction occur and the oxide layer falls off, exposing titanium alloy to bodily fluids [16] Preventing micromotion is thus the best way to avoid damage within modular junctions. Since $\mathrm{Co}-\mathrm{Cr}$ alloy has a twice as high module of elasticity compared to titanium alloy, there should be less micro movement than with titanium alloy exchangeable necks. However, with neck fracturing already at 2 years after implantation because of an added galvanic corrosion, $\mathrm{Co}-\mathrm{Cr}$ necks have not proven to be a safe alternative [7].

Other factors that may escalate fretting corrosion include patient BMI, lateral offset, varus femoral stem positioning, longer necks and larger heads, time since implantation and inconsistency in the assembly of modular heads including the force of impaction, the vector of the applied force, and contamination of the interface [3]. A crack can start on the medial proximal side of the neck-stem taper surface [17]. After the initial crack is made, the corrosion can continue without additional external loads on the femoral neck. This type of autocatalytic corrosion is a result of chemical changes within the crevice fluid [17].

Several studies report complications after implantation of bi-modular femoral stems with symmetrically oval Morse taper joints in primary THA. Grupp et al. followed 5000 bi-modular Metha Short Hip stems (Aesculap AG, Tuttlingen, Germany) implanted between 2004 and 2006 and found that $1.4 \%$ of the titanium alloy necks failed after 2 years [2]. Bernstein et al. reported 86\% clinical failure rate of the Rejuvenate bi-modular stem implant with Co$\mathrm{Cr}$ neck (Stryker Orthopaedics, Mahwah, New Jersey) at $4.2 \pm 0.6$ years mean final follow up [18]. Pour et al. followed 277 patients after Profemur (successor of An.C.A. Fit prosthesis with the same oval Morse taper neck-stem junction) bi-modular series stem implantation and found 6\% neck fractures at 50 months mean follow up [19]. Finally, Kovač et al. studied the long-term behaviour of the Profemur Z modular stem on a national basis (2767 hips followed) and found out that the mean time for bimodular femoral neck fracture $(0.83 \%)$ was 4.7 years ( $\mathrm{SD} \pm 2.2$ years) [4]. Furthermore, long neck, $\mathrm{Co}-\mathrm{Cr}$ modular neck, which was introduced by the producer (Wright Medical Technology, now MicroPort Orthopedics Inc.) in 2010 to reduce the failure rate of titanium alloy made necks, and male gender represent the independent risk factors for modular neck fracture [4]. In 


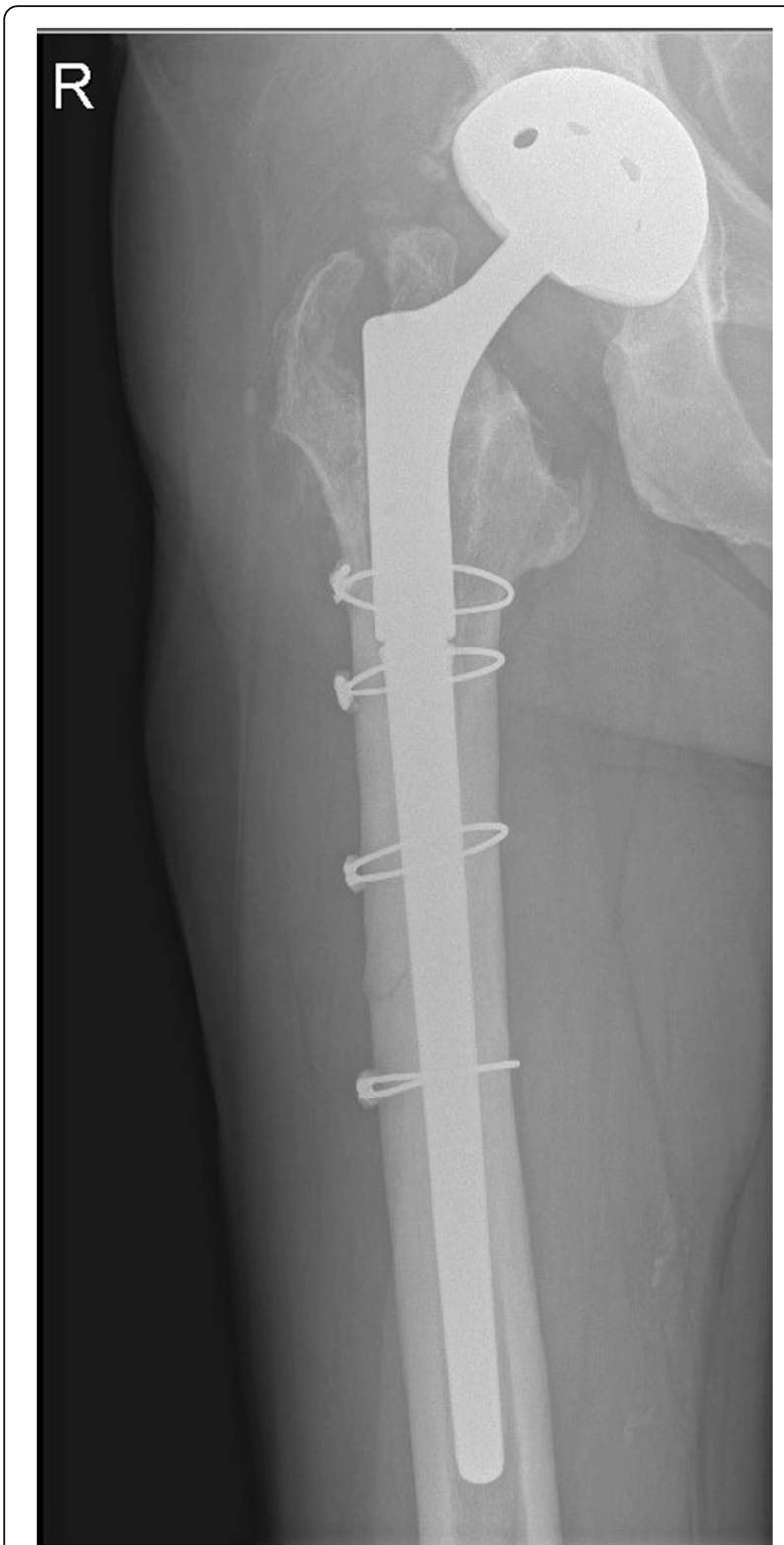

Fig. 4 X-ray of the right hip 14 months after last revision

contrast, Pelayo-de-Tomás et al. found only 1 modular neck fracture in their cohort of 317 consecutive patients followed for 6.1 (range, 2-8) years after bi-modular stem (H-MAX M, Lima, San Danielle, Italy) THA [20]. The authors attributed the discrepancy between the H-MAX M model and other commercially available modular stems to the elliptical dual radius neck-stem coupling causing fever micro-movements [20].

In 2009, Blakey et al. conducted a study on 319 patients that were treated with primary THA using uncemented hydroxyapatite-coated An.C.A. Fit modular femoral stem due to osteoarthritis [21]. Five years after implantation, the authors clinically and radiographically examined 212 males and 107 females with a mean age of
64.4 years. Oxford Hip Score got significantly better (from mean 41 points to 20 points). There were two cases of aseptic loosening. They concluded that there were no clinical or radiographic complications due to modularity [21]. In 2017, Toni et al. reported on clinical and radiographic outcomes of 235 patients $13-18$ years after An.C.A. Fit prosthesis implantation with ceramicon-ceramic $(\mathrm{CoC})$ bearing and noted no modular neck fracture; $93.2 \%$ of the implanted THA were still functioning well [22]. However, this case report demonstrates that titanium-titanium alloy modular-neck implants in primary THA are not so uniformly good and complication-free.

Lex et al. recently published a systemic review of 14 studies (12 case series and 2 joint registry analyses) on current-generation primary THA using titaniumtitanium alloy modular-neck implants, including An.C.A. Fit [23]. The mean follow-up duration of the studies was 5.7 years and they included 591,025 patients, of which 21,841 underwent modular neck THAs and 569,184 received a fixed-neck prosthesis. Even though the authors have found the overall mean revision rate $(3.95 \%)$ and the mean revision rate for fracture of the modular neck component $(0.43 \%)$ for modular prosthesis acceptable, they consider modular prostheses to be a viable management option only in patients with considerable anatomical hip deformities that cannot be corrected with standard fixed-neck implants. The review also points out two national registry reports, which revealed that modular neck prostheses had a higher revision rate compared to traditional, fixed-neck prostheses in patients with osteoarthritis [24].

To our knowledge, the present is the first reported case with bilateral bi-modular femoral neck fracture in a single patient. The modular neck fracture in the presented case occurred relatively early on the left and later on the right side. Beside the variation in the size of acetabular and stem components, the only difference between the implants was in the bearing couple, which was ceramic-on-polyethylene (CoP) on the left side and metal-on-polyethylene (MoP) on the right side. Together with slight variation between implant position and offset, these dissimilarities could be responsible for different timing at which modular neck fracture occurred. However, Frisch et al. have shown that the shape of the neck and stem tapers deviate from ideal design dimensions, contributing to relative motions between the neck and the stem and may place the implants at higher risk for failure [24]. This means that such catastrophic failures can occur unpredictively in otherwise normally functioning implant(s).

The patient in this report was a younger active male with a BMI in the obese range. He had a long modular neck implanted in combination with a long head - all of 
which are known risk factors for modular neck fracture and therefore make the patient at risk for neck failure [5, $7,10,19]$. The fatigue strength of TiAl6V4 is about 400 $\mathrm{MPa}$. In heavier and more active patients this threshold can be exceeded because very high tensile stresses occur on long necks in combination with long femoral heads $[10,25,26]$. This stress can open microcracks on the surface and stress fields inside the prosthesis add to crack propagation after its initiation. The patient was hospitalized for 208 days altogether due to bilateral bimodular prosthesis failure, which profoundly impacted his social life and exposed him to other health problems and threats that arise with more prolonged hospitalizations. Since higher septic complications after THA revision surgeries are well established, modular neck fracture per se could not be blamed for septic complications that developed after revisions of both sides in presented patient [27, 28]. However, more complications also mean higher costs of treatment, which is not beneficial for the health care system. If a high percentage of bi-modular stems started to fail, this could become a major public health issue. Continued usage of bimodular stems for primary THA is therefore not only a problem associated with more treatment complications and patient suffering but also an economic problem and a threatening public health concern.

In conclusion, the patient could have avoided all the unnecessary complications and had a better quality of life if he were primarily treated with monoblock stems instead.

\section{Abbreviations \\ THA: Total hip arthroplasty; MACC: Mechanically assisted crevice corrosion; BMI: Body mass index; TiAl6V4: Titanium-aluminium-vanadium; Co-Cr: Cobalt- chromium; DAIR: Debridement, antibiotics and implant retention; HHS: Harris Hip Score; UCLA: University of California at Los Angeles; SF 36: Short form 36; CCD: Centrum-collum-diaphyseal; MPa: Megapascal; CoC: Ceramic-on- ceramic; MoP: Metal on polyethylene; CoP: Ceramic on polyethylene}

\section{Acknowledgements}

Authors acknowledge Mrs. Tina Fokter for her help in preparing the manuscript.

\section{Authors' contributions}

SKF: conception, design, collection of data, data analysis \& interpretation, performing second revision of right THA, writing of manuscript for publication, final approval of manuscript. NG: conception, design, and final approval of manuscript. JP: conception and final approval of manuscript. JS: collection of data, writing of manuscript for publication, final approval of manuscript. JZ: collection of data, writing of manuscript for publication, final approval of manuscript. ZK: performing fourth revision of the left THA, first revision of the right THA, following the patient, final approval of manuscript.

\section{Funding}

Authors acknowledge the Slovenian Research Agency for founding members of research program P2-0137 Numerical and Experimental Analysis of Nonlinear Mechanical Systems.

\section{Availability of data and materials}

This is a case report of a single patient; to protect privacy and respect confidentiality, none of the raw data has been made available in any public repository. The original operation reports, intraoperative photographs, imaging studies and outpatient clinical records are retained as per normal procedure among the medical records of our institution. All data concerning the case are presented in the manuscript.

\section{Declarations}

\section{Ethics approval and consent to participate}

All procedures performed in studies involving human participants were in accordance with the ethical standards of the institutional and/or national research committee and with the 1964 Helsinki declaration and its later amendments or comparable ethical standards. Institutional Review Board (IRB) approval was obtained to perform this study. Informed consent was obtained from the patient included in the study.

\section{Consent for publication}

Informed consent was obtained from the patient included in the study. The patient has given his written permission to publish his data and $\mathrm{x}$-rays.

Written consent is being held at the Department of Orthopaedics University Medical Centre Maribor and is available for review by the editor.

\section{Competing interests}

The authors declare that they have no conflict of interest.

\section{Author details}

'Department of Orthopaedic Surgery, University Medical Centre, 5 Ljubljanska street, SLO-2000 Maribor, Slovenia. ${ }^{2}$ Faculty of Mechanical Engineering, University of Maribor, 17 Smetanova street, SLO-2000 Maribor, Slovenia. ${ }^{3}$ Slovenj Gradec General Hospital, 1 Gosposvetska road, SLO-2380 Slovenj Gradec, Slovenia.

Received: 10 August 2020 Accepted: 31 March 2021

Published online: 16 April 2021

\section{References}

1. Traina F, De Clerico M, Biondi F, et al. Sex differences in hip morphology: is stem modularity effective for total hip replacement? J Bone Jt Surg Am. 2009:91(Suppl 6):121-8. https://doi.org/10.2106/JBJS.I.00533.

2. Grupp TM, Weik T, Bloemer W, et al. Modular titanium alloy neck adapter failures in hip replacement-failure mode analysis and influence of implant material. BMC Musculoskelet Disord. 2010;4(11):3.

3. Pourzal R, Lundberg HJ, Hall DJ, Jacobs JJ. What factors drive taper corrosion? J Arthroplast. 2018;33(9):2707-11. https://doi.org/10.1016/j.arth.2 018.03.055.

4. Kovač S, Mavčič B, Kotnik $M$, et al. What factors are associated with neck fracture in one commonly used bimodular THA design? A multicenter, nationwide study in Slovenia. Clin Orthop Relat Res. 2018;477:1324-32.

5. Vanbiervliet J, Somers JFA. Excellent mid-term results of a new polished tapered modular cemented stem: a study of 113 hip replacements with minimum 5-year follow-up. Hip Int. 2017;27(5):455-9. https://doi.org/10.53 01/hipint.5000486.

6. Wright C, Sporer S, Urban R, et al. Fracture of a modular femoral neck after total hip arthroplasty. J Bone Jt Surg Am. 2010;92(Suppl 6):1518-21. https:// doi.org/10.2106/JBJS.I.01033.

7. Fokter SK, Rudolf R, Moličnik A. Titanium alloy femoral neck fracture-clinical and metallurgical analysis in 6 cases. Acta Orthop. 2016;87(2):197-202. https://doi.org/10.3109/17453674.2015.1047289.

8. Duwelius P, Burkhart B, Carnahan C, et al. Modular versus nonmodular neck femoral implants in primary total hip arthroplasty: which is better? Clin Orthop Relat Res. 2013:472:1240-5.

9. Mumme T, Müller-Rath $\mathrm{R}$, Jakobi N, et al. In vitro serum levels of metal ions released from orthopaedic implants. Eur J Orthop Surg Traumatol. 2004;15: 83-9.

10. Zajc J, Predan J, Gubeljak N, Fokter SK. Modular femoral neck failure after revision of a total hip arthroplasty: a finite element analysis. Eur J Orthop Surg Traumatol. 2018;29:717-23.

11. Hsu AR, Gross CE, Levine BR. Pseudotumor from modular neck corrosion after ceramic-on-polyethylene total hip arthroplasty. Am J Orthop. 2012; 41(9):422-6.

12. Lindgren J, Brismar B, Wikstrom A. Adverse reaction to metal release from a modular metal-on-polyethylene hip prosthesis. J Bone Jt Surg. 2011;93B(10):1427-30. https://doi.org/10.1302/0301-620X.93B10.27645. 
13. Gill I, Webb J, Sloan K, et al. Corrosion at the neck-stem junction as a cause of metal ion release and pseudotumour formation. J Bone Jt Surg. 2012;94B(7):895-900. https://doi.org/10.1302/0301-620X.94B7.29122.

14. Cooper $H$, Urban $R$, Wixson $R$, et al. Adverse local tissue reaction arising from corrosion at the femoral neck-body junction in a dual-taper stem with a cobalt-chromium modular neck. J Bone Jt Surg Am. 2013;95(10):865-72. https://doi.org/10.2106/JBJS.L.01042.

15. Swaminathan V, Gilbert JL. Fretting corrosion of CoCrMo and Ti6Al4V interfaces. Biomaterials. 2012;33(22):5487-503. https://doi.org/10.1016/j. biomaterials.2012.04.015.

16. Jauch SY, Huber G, Haschke H, Sellenschloh K, Morlock MM. Design parameters and the material coupling are decisive for the micromotion magnitude at the stem-neck interface of bi-modular hip implants. Med Eng Phys. 2013;36(3):300-7. https://doi.org/10.1016/j.medengphy.2013.11.009.

17. Gilbert JL, Mali S, Urban RM, Silverton CD, Jacobs JJ. In vivo oxide-induced stress corrosion cracking of Ti-6Al-4V in a neck-stem modular taper: emergent behaviour in a new mechanism of in vivo corrosion. J Biomed Mater Res B Appl Biomater. 2011;100B(2):584-94.

18. Bernstein $D$, Meftah $M$, Paranilam J, Incavo $S$. Eighty-six percent failure rate of a modular-neck femoral stem design at 3 to 5 years. J Bone Jt Surg. 2016;98(12):e49. https://doi.org/10.2106/JBJS.15.01082.

19. Pour A, Borden R, Murayama T, et al. High risk of failure with bimodular femoral components in THA. Clin Orthop Relat Res. 2016;474(1):146-53. https://doi.org/10.1007/s11999-015-4542-0

20. Pelayo-de-Tomás JM, Rodrigo-Pérez JL, Novoa-Parra CD, Lizaur-Utrilla A, Morales-Suárez-Varela M, Blas-Dobón JA. Cementless modular neck stems: are they a safe option in primary total hip arthroplasty? Eur J Orthop Surg Traumatol. 2018;28(3):463-9. https://doi.org/10.1007/s00590-017-2071-0.

21. Blakey CM, Eswaramoorthy VK, Hamilton LC, et al. Mid-term results of the modular ANCA-fit femoral component in total hip replacement. J Bone Jt Surg. 2009;91:1561-5.

22. Toni F, Giardina G, Guerra A. 3rd generation alumina-on-alumina in modular hip prosthesis: 13 to 18 years follow-up results. Hip Int. 2017;27(1):8-13. https://doi.org/10.5301/hipint.5000429.

23. Lex JR, Welch MD, Abbas S, Edwards TC, Stavropoulos NA, Babis GC Systematic review of primary total hip arthroplasty using titanium-titanium modular-neck prostheses: the true risk of revision. Hip Int. 2020;16: 1120700020916870.

24. Frisch N, Lynch J, Pourzal R, Banglmaier R, Silverton C. Dual-taper modular hip implant: investigation of 3-dimensional surface scans for component contact, shape, and fit. Arthroplasty Today. 2018;4(3):370-5. https://doi.org/1 0.1016/j.artd.2018.06.001.

25. Bergmann G, Graichen F, Rohlmann A. Hip joint loading during walking and running, measured in two patients. J Biomech. 1993;26(8):969-90. https:// doi.org/10.1016/0021-9290(93)90058-M.

26. Bergmann G, Graichen F, Rohlmann A, Bender A, Heinlein B, Duda GN, et al. Realistic loads for testing hip implants. Biomed Mater Eng. 2010;20(2):65-75. https://doi.org/10.3233/BME-2010-0616.

27. Badarudeen S, Shu Albert C, Ong KL, Baykal D, Lau E, Malkani AL. Complications after revision total hip arthroplasty in the medicare population. J Arthroplast. 2017;32(6):1954-8. https://doi.org/10.1016/j.arth.2 017.01.037.

28. Jafari SM, Coyle C, Mortazavi SMJ, Sharkey PF, Parvizi J. Revision hip arthroplasty: infection is the most common cause of failiure. Clin Orthop Relat Res. 2010;468(8):2046-51. https://doi.org/10.1007/s11999-010-1251-6.

\section{Publisher's Note}

Springer Nature remains neutral with regard to jurisdictional claims in published maps and institutional affiliations.

Ready to submit your research? Choose BMC and benefit from:

- fast, convenient online submission

- thorough peer review by experienced researchers in your field

- rapid publication on acceptance

- support for research data, including large and complex data types

- gold Open Access which fosters wider collaboration and increased citations

- maximum visibility for your research: over $100 \mathrm{M}$ website views per year

At $\mathrm{BMC}$, research is always in progress.

Learn more biomedcentral.com/submissions 